\title{
Effect of Rhizosphere Micro-Environment on Purification Potential of Constructed Wetlands
}

\author{
Junjie You ${ }^{1 * *}$, Yanli Ding ${ }^{1}$,Shaoyuan Bai ${ }^{1,2}$, Xuefen $\mathrm{Li}^{2}$, and Lin Sun ${ }^{2,}$ \\ 1Guangxi Scientific Experiment Center of Mining, Metallurgy and Environment, Guilin University of Technology, Guilin 541004, China \\ 2 Guangxi Key Laboratory of Environmental Pollution Control Theory and Technology, Guilin 541004,China
}

\begin{abstract}
Plants play an important role on constructed wetland (CW) purification, especially for its rhizosphere micro-environment. Oxygen supplying, , microbial biodegradation, hydraulic transmission and impovement nutrient are all closely related to the root micro-environment. However, after a period of running, plant residues and root exudates may affect the treatment performance of CWs, and clogging occurs. This paper reviews the both the positive and the negative roles of root micro-environment to develop promising strategies and proper management techniques in CWs.
\end{abstract}

\section{Introduction}

Constructed wetlands are natural wetland built by artificial and controlled by the soil - plant - ecosystem formed by microbes, using direct and synergies ecosystems physical, chemical and biological through filtration, adsorption, precipitation, ion exchange, plant uptake and microbial degradation to achieve efficient purification of sewage treatment in a new sewage (waste) water treatment technology.

Plants play a crucial role in the CWs, root microenvironment influences the wastewater degradation performance.In this environment, the plant not only can directly absorb pollutants, as well as provide significant microbial attachment surface, while the use of selfpurification process to provide energy for the photosynthesis and a carrier[1].In plant growth and development process, the roots of plants and soil as an important interface, not only is the absorption and metabolism of organs, or strong secretion organs[2,3]. Runying[4]researched that the main factor influencing the microbial activity in the wetland systemwas the presence of plants. The plantspecies was the second factor, and the plant development stages the third. Plant roots can release sugars, alcohols and acids and other secretions to the soil environment, decomposing fine roots for soil organic carbon supplement and strengthen the microbial mineralization of organic contamination rate[5].Growth and development of plant roots and root exudates of organic and inorganic compounds that stimulate the rhizosphere microbial proliferation of important energy and nutrient source. The more root exudates, the more vigorous growth of microorganisms, and the type of root exudates also determines the type of rhizosphere microorganisms [6].

In addition to root exudates affect rhizosphere microbial populations and species, it has some influence on the microbial metabolism and growth. In the longterm operating conditions, different wetland plants will form a unique microbial communities[7,8].Effects due to different microbial communities play in the water treatment process varies, select the appropriate wetland plants to promote the formation of efficient microbial communities become effective way to improve the processing efficiency of wetlands[9].

However, due to the long run of constructed wetlands, there is a corresponding clogging problem. Inorganic poetry jam subject matter, but the presence of organic matter is the main cause for blockage formation, Which is contributed by plants: one plant root exudates and plant residues are an integral part of the obstruction [10], and second, plant roots can secrete some oxygen and nutrients as a carbon source, stimulate rhizosphere microorganisms growth, also have an impact on wetlands blocked [11].This paper describes the root micro-environment and its roles in CWs, additional, the negative impact of plant roots are concerned.

\section{The Rhizosphere Micro-Environment in CWS}

\subsection{Oxygen supply}

Constructed wetland system can replace the traditional process plants in which the aerator is essential. As reported earlier [12], the total nitrogen (TN) removal rate in CWs with plants was significantly higher than that of non-plant systems. Oxygen produced by photosynthesis of wetland plants released through the organization into the root zone or rhizosphere and formed an aerobic environment, which can promote bacterial degradation capability of organic matter and enhance nitrification growth. It was found that plant roots mainly distributed around $15 \mathrm{~cm}$ deep from the surface, the filler color of this zone is dark than the other zones, it also indicated the oxygen released by the roots [13].Both shallow roots and large amounts of non-wetland plants are all affect oxygen diffusions, an efficient oxygen transfer need the following steps:

- Employed the native plants, these plants can constantly grow in the water saturated conditions;

- The water must be kept low in order to make a deeper rooted plants when transplanted a new plant ;

- During the early days after transplant, a distance between the plant roots and water level is needed; 
- Weeds and plant debris ought to be removed to ensure the contact between air and matrix.

\subsection{Providing microbial habitat}

Microbial communities in the CWs are extremely rich. Aquatic plant roots often form a network like structure caused the aerobic, anoxic and anaerobic zones formed near or far from the plant roots, which provides a suitable living environment for a variety of microorganisms, that are the decomposers in CWs. In addition, because the root system of plants can secrete a variety of vitamins, enzymes, plant growth regulators and amino acids and other substances, to attract the microorganisms in the rhizosphere and promote their growth and development, and then to the rhizosphere microbial species, quantity and distribution[14].It was reported that bacterial counts in the CWs with plants were significantly higher than that of non-plant systems, furthermore, the microorganism amounts of plant roots are one to two orders of magnitude higher than that of substrate. Root exudates of plants also can promote the growth of specific bacteria for nitrogen and phosphorus degradation, and thus improve the purification rate indirectly [15].

Bacterial communities are significant differences between CWs with and without plant, while there was no significant difference between CWs with different plants [16]. The study also found that anoxic zones formed a little far from the root hairs, and further regions are completely anaerobic conditions. The debris and sediment-rich litter layer, which contains a large number of available carbon source, which in turn provides the denitrifying conditions $[17,18]$. There by nitrifying bacteria, denitrifying bacteria and other bacteria turned the organic nitrogen, phosphorus and other nutrients into a mineral form of ammonium ion, nitrate ion, phosphate ion and then uptake, absorbed or precipitated in the system [19].

\subsection{Hydraulic transport function}

Roots or root hole in the substrate of CWs were known as the unseen mass transport "highway", which are benefit for the transport of oxygen and other nutrients[20]. Plant root hole is an important type of macropore matrix.On the one hand,in the priority matrix flow,solute transport ,migration and degradation of environmental pollutants has an important role.On the other hand,it can be seen as an important interface with plant roots matrix between the matrix also increased air interface. It plays an important role in the rhizosphere micro-environment. The growth of plants accelerate the hydraulic transmission of the substrate, and the capacity of the water increases when the plants mature.Even when the root and root system decay, there are many gaps and channels are conducive to the hydraulic transmission of the matrix.

\subsection{Improvement of nutrient}

Under nutrient stress conditions, plant roots can secrete a variety of active or passive organic acids, acid phosphatase enzymes material promoting rhizosphere soil nutrients cured activation easy plant utilization, overcome or alleviate nutrient deficiency[21]. Exudates organic anion with $\mathrm{Al}, \mathrm{Fe}$ and $\mathrm{Ca}$ and other metal elements form chelates release rhizosphere soil insoluble phosphorous, improving plant phosphorus deficiency state[22]. Plant roots secrete material can reduce soil $\mathrm{pH}$, resulting in increased solubility of calcium sulfate, increasing soil phosphorus content[23]. Among them, the acid phosphatase secreted from roots of a plant for the lack of the earliest and most vigorous reaction of phosphorus stress on one hand, it can promote plant reuse an organic phosphorus, it also can promote soil organic phosphorus ore And decomposition of phosphate plant has a very important role.

\section{Clogging of Rhizosphere Micro- environment in CWS}

As descibed above, penetration of the substrate by the plant roots and root rot, formed in the substrate of many tiny air chamber or clearance, will reduce the compactness of matrix, improve the osteoporosis of substrate, so as to make the hydraulic conductivity and ventilation conditions of wetlands to strengthen and sustain, and ensure the continuous operation and treatment effect of CWs. But,the decline of wetland plants residues, root and root secretion can cause the increased amount of organic matter accumulated in the system. Nguyen [24] researched that wetland packing top $10 \mathrm{~cm}$ thickness within dense plant roots can significantly limit water infiltration, these roots after the substance led to massive accumulation of organic matter decay, increased siltation of wetlands clogging; Mo [25] found by planting grass and disadvantages of Scirpus Tabernaemontani, wet permeability of matrix also with kinds of plants is closely related to. According to IWA (2000), a dense macrophyte stand will have 500 - $5000 \mathrm{~g}$ dry weight (DW) per $\mathrm{m} 2$ of subsurface roots andrhizomes, which provides additional surface area for accumulation and occludes one quarter to one third of pore volume in the root-zone. Root material contributes to subsurface clogging and leaf litter-fall contributes to surface clogging, with Kadlec and Wallace stating that typically $5-15 \%$ of plant detritus is recalcitrant[26].Tanner[27] researched that vegetated wetlands than the same conditions no plant system after the clogging of substrate high amount of organic matter accumulation between 1.2 $\sim 2.0 \mathrm{~kg} / \mathrm{m} 2$, presumably part of the higher organic matter is contributed by the plants.Organic matter accumulation rates of $1300-3000 \mathrm{~g} / \mathrm{m} 2 \cdot \mathrm{yr}$ were recorded but only $400-1600 \mathrm{~g} / \mathrm{m} 2 \cdot \mathrm{yr}$ could be directly attributed to wastewater loading, and only $4 \%$ of pore blockage was due to live root penetration[27].Vegetated wetlands accumulation of organic matter and oxygen-rich environment, aerobic microorganisms multiply,thereby undermining the ecological balance within the matrix, 
increasing the probability matrix between clogging, and may reduce the removal of contaminants.In addition,it has been postulated that the higher hydraulic resistance in the vegetated upper gravel layer causes flow to shortcircuit along the less resistive bottom layer.

In order to reduce the impact of the plant on the clogging, consider the choice of rhizosphere reoxygenation ability secrete less refractory material plant as a wetland plants; while harvesting the aerial parts of the plants on a regular basis and regular removal system mucosal surface accumulation of organic matter.

\section{Conclusion and Outlook}

As expained before,the most important components of the plant, clean water plays an irreplaceable role in the CWs, the rhizosphere micro-environment very important impact on sewage treatment. The more vigorous growth, more developed root system of the plant, its ability to purify water, improvement of nutrient, the greater the role of oxygen and root penetration. At the same time, we are in different sewage, different seasons, different sizes of CWs, which should choose a different adaptation of plants, effectively control the wetland clogging and improve its operational life. On the other hand, plant root exudates could improve the nutrient stress, and the study on root exudates and rhizosphere micro-environment also gradually be taken seriously these need to do more exploration in plant terms. These all need to do more to explore in terms of plants, hoping to strengthen research in the following areas:

- Future studies should also intend to focus on exploring the patterns of microbial ecology and their interactions, associated As toxicity on plants and microbial biomass and volatilization of as under dynamic redox conditions within the rhizosphere of constructed wetland system.

- Composition clear root exudates and its role in the rhizosphere micro-ecosystem, the use of molecular biology research methods and other plants release root exudates mechanism maladaptive environment, provide the basis for the selection of wetland plants.

- By wetland plant species selection or management of the plant to stimulate new root growth to improve the transfer of oxygen. In many cases, the growth of plant roots rot restricted or circumstances appear, have an impact on the foundation of micro-organisms, thus affecting the effect of artificial wetland wastewater treatment. So deep roots to expand the research should be carried out in favor.

- Build a stable wetland plant biological systems, including the combination of tree, shrub and grass, and other plants interplanted warm and cold season.

- Decontamination further study the mechanism of plant systems, including the effect of plants, plant adaptation mechanisms of pollutants in the transfer and transformation of plants and harvested plants of treatment.

\section{Acknowledgements}

The work was funded by the National Natural Science Fo undation of China (No. 51408147,51168012,41404116) a nd Guangxi Natural Science Foundation (No. 2014GXNS FBA118234), and supported by the project of high level innovation team and outstanding scholar in Guangxi colle ges and universities.

\section{References}

[1] LU Songwu, HU Hongying, SUN Ying xue,et al. Study on the growth characteristics and root exudates of three wetlands plants at different culture conditions [J]. Environmental Science, 30(7):19011905(2009)(In Chinese)

[2] HUANG Juan, WANG Shihe, YAN Lu,et al. Plant photosynthesis andits influence on removal efficiencies in constructed wetlands[J].Ecological Engineering, 36(8):1037-1043(2010)(In Chinese)

[3] CHEN Bo, LIN Jianguo, CHEN Qing. Root exudates and its effect on soil pollutants [J]. Hubei Agricultural Sciences, 49 (3): 718-721(2010)(In Chinese)

[4] Runying Wang, Virginie Baldy, Claude Périssol, Nathalie Korboulewsky,Influence of plants on microbial activity in a vertical-down flow wetland system treating waste activated sludge with high organic matter concentrations. Journal of Environmental Management,95:S158-S164(2012)

[5] LIANG Xue , HE Feng, XU Dong, et al. Plant function and selection for constructed wetlands [J]. Journal of Hydroecology ,33(1): 131-138(2012)(In Chinese)

[6] HE Huan , WANG Zhan, HU Dong, et al. Progress on interactions between root exudates and rhizosphere mi croorganisms [J]. Journal of Hebei Agricultural Science,15 (3): 69-73(2011).(In Chinese)

[7] ZHAO Qingjie. Study on the soil microbial diversity in therunning constructed wetland cultivated with four plants [J]. Journal of Shanghai Jiaotong University:Agricultural Science, 29(3): 4752(2011)(In Chinese)

[8] FANG C W, RADOSEVICH M, FUHRMANN J J. Characterization of rhizosphere microbial community structure in five similar grass speciesusing fame and biologyanlyses [J].Soil Biology and Biochemistry, 33 (4): 679- 682(2001)

[9] HUANG Juan, WANG Shihe, ZHONG Qiushuang, et al .Influence of plant ecophysiology characteristics onnitrogen removal effect in constructed wetlands [J].Ecology and Environmental Sciences, 18 (2): 471-475(2009)(In Chinese)

[10] Pedescoll A., Corzo A.l.,lvarez E.A., et al. The effect of primary treatment and flow regime on clogging development in horizontal subsurface flow constructed wetlands: An experimental evaluation[J]. Water Research. 3579-3589(2011)

[11]Wang R., Baldy V., Périssol C., et al. Influence of plants on microbial activity in a vertical-down flow wetland system treating waste activated sludge with 
high organic matter concentrations. Journal of Environmental Management. 95,158-164(2012)

[12] ZHANG Jiaoyao,XIA Shenglin,QIU Keming,et al. Bacterial undercurrent artificial wetland sewage treatment system to remove nitrogen and nitrogen transformation[J].Journal of Environmental Sciences. 19(3):323-327(1999).

[13] Whitney D,Rossman A,Haden N. Evaluating an existing subsurface flow constructed wetland in Akumal,Mexico[J].Ecological Engineering ,20:105111(2003) (In Chinese)

[14]WANG Yanping, WANG Huatian. Allelochemicals from roots exudation and its environment behavior in soil. Chinese Journal of Soil Science, 41(2): 501507(2010)

[15]ZHANG Hong,CHEN Guangrong. A preliminary study of the relationship between the two wetlands in nitrogen, phosphorus and bacterial purification rate distribution[J].Journal of central China normal university,33(4):575-578(1999).(In Chinese)

[16]FU Rongbing,YANG Guozhen,GU Guowei,et al. Constructed wetland substrate the micro-organisms and purification effect correlation analysis[J]. Environmental Science Research, 18(6):44-49(2005).

[17] Philip A,M Bachhand Alex .Denitrification in constructed free-water surface wetlands:I very high nitrate remove rate in macrocosm study [J].Ecological Engineering 14:9-15(2000)

[18] Achintya N,Bzebaruah,Tian C Zhang · pH, redox,and oxygen microprofiles in rhizosphere of bulrush(Scripus validus)in constructed wetland treating municipal wastewater[J]. Biotechnology an Bioengineering, 88(1):60-70(2004)

[19]ZHU Li,NIE Jing,WANG Cheng,et al. Design of new wetland project. Journal of Ecology, 23 (3): 144 -148(2004)(In Chinese)

[20] QI Zemin , QING Donghong. Root exudates and their ecological function[ J] . Journal of Neijiang Teachers College, 20(2): 68-74(2005)(In Chinese)

[21] YANG Bo . A study on the regulation mechanism of Al-inducedsecretionwith organic acids metabolismin RYE. Nanning: Guangxi University(2006)(In Chinese)

[22] TIAN Zhongmin . The advance on nutrient of phosphorus of plant[J]. Journal of Xianyang Teachers College, 16(6): 60-65(2001)(In Chinese)

[23]Long M.Nguyen. Organic matter composition, microbial biomass and microbial activity in gravel-bed constructed wetlands treating farm dairy waste waters [J].Ecological Engineering,16 (2): 199-221(2000)

[24]Feng Luan Mo, Ping Wang , Shulan Li , et.al.Maintenance of constructed wetland system [J]. Yunnan Environment Science,23 ( B04):58(2004)(In Chinese)

[25]LI Guibao, ZHOU Huaidong, YI Chengqing. Wetland plant and its root hole in the nonpoint source pollution control in the future[J].China Water Conservancy, A s: 51 -52, 61(2003)(In Chinese)

[26]Kadlec, R.H., Wallace, S.D., Treatment Wetlands, seconded. CRC Press, BocaRaton, FL(2009)
[27] Tanner C, Sukias J P S, Upsdell M P. Organic matter accumulation during maturation of gravel-bed consructed wetlands treating farm dairy wastewaters[J].WaterResearch,36(10):30463054(1988) 